\title{
IDENTIDADE FRATURADA: \\ O DESMEMORIAMENTO DA "ADESÃO DO PARÁ" NO ENSINO DE HISTÓRIA
}

\author{
FRACTURED INDENTITY. \\ THE DISMEMBERMENT OF "ADHESION OF PARÁ" IN HISTORY TEACHING
}

Adilson J. I. Brito ${ }^{1}$

\begin{abstract}
RESUMO: Parece relativamente assente que uma das raízes do conhecimento histórico escolar está relacionada ao comprometimento intelectual com a edificação da Nação, a partir da construção da memória e identidade coletivas. Como disciplina de formação básica pública, a História deveria comemorar a "história nacional", e os seus desdobramentos regionais e locais, através do incentivo à aprendizagem genealógica de um passado comum. Esse quadro tem sofrido grandes mudanças na atualidade. A história ensinada na Escola tem se distanciado desse historicismo nacionalista, na qual a formação básica pouco contempla a aprendizagem significativa da história, levando a processos de desmemoriamento e despertencimento de bens identitários nacionais, regionais e locais entre os agentes da Educação no espaço escolar. Este artigo pretende adentrar nessa discussão, a partir da investigação sobre as "fraturas" nas experiências de ensino e aprendizagem de um processo histórico regional específico, a "Adesão do Pará à Independência do Brasil", no cotidiano de uma escola pública de ensino médio da periferia do município de Ananindeua-PA, na Amazônia brasileira.
\end{abstract}

Palavras-chave: Ensino de História. Educação básica. Ensino Médio. Adesão do Pará.

\begin{abstract}
It seems relatively settled that one of the roots of the school historical knowledge is related to the intellectual commitment with the edification of the Nation, from the construction of collective memory and identity. As a discipline of basic public formation, History should commemorate national history, and its regional and local developments, by encouraging the genealogical learning of a common past. This picture has undergone great changes in the present time. The History taught in the High School has distanced itself from this genealogical function, in which the basic formation does not include the significant learning of history, leading to processes of dismemberment and unawareness of national, regional and local identity goods among educations agents in the school space. This article intends to enter into this discussion, about "fractures" in teaching and learning experiences of a specific regional historical process, the "Adherence of Pará to Brazil's Independence", in the daily life of a public High School in the outskirts of the municipality of Ananindeua-PA, in the brazilian Amazon.
\end{abstract}

Keywords: History teaching. Basic Education. High School. Adherence of Pará.

1 Professor Doutor Efetivo do curso de Licenciatura em História da Universidade Federal do ParáCampus de Ananindeua; Coordenador do Laboratório de Ensino de Humanidades Amazônicas (LABHAM); Coordenador do Projeto de Pesquisa "Adesão do Pará à Independência: memória e ensino de História"; Coordenador do Grupo de Trabalho "Memória e Comemorações Nacionais". 


\section{Introdução}

Ao iniciar a análise de dados de uma pesquisa escolar em uma tradicional instituição pública de Ensino Médio de Ananindeua-Pará, sobre o conhecimento histórico acerca do Dia 15 de Agosto, que remete ao processo de Independência e à formação da nacionalidade brasileira, nos deparamos com algumas preocupantes respostas dos estudantes. "Acredito que seja o Feriado do Dia do Índio"; "Não faço ideia; não lembro no momento"; "Não tenho certeza, mas eu acho [...] [que] é comemorado o Dia dos Pais"; "Nenhum, nem sabia que tinha feriado nesse dia". Os que conseguiram identificar corretamente que o dia 15 de Agosto comemora a "Adesão do Pará à Independência do Brasil", curiosamente fizeram referências diversas acerca do tempo e do lugar de ensino e aprendizagem: "Aula de História não"; "[estudei na aula de] Língua Portuguesa"; "Não fizeram nada em sala de aula"; "[aula de] Geografia"; "Foi ensinado na disciplina história, no meu ensino fundamental II"; "Não lembro". Entre os estudantes que identificaram o acontecimento comemorado anualmente em 15 de agosto, pouquíssimos souberam desenvolver informações básicas sobre o processo histórico e o porque de sua celebração. A maioria optou, nesse sentido, por deixar em branco o espaço destinado à justificativa, silêncio que indica um eloquente desinteresse/esquecimento sobre um dos períodos cruciais da história brasileira na Amazônia. ${ }^{2}$

Essas respostas representam o esquecimento extremo sobre um dos marcos da nacionalidade no norte do Brasil. Todavia, "não lembro" talvez não seja uma resposta assim tão incomum e incoerente entre gestores escolares, coordenadores pedagógicos e professores da rede pública de Ensino Médio, comumente encerrados no cotidiano mais imediato da escola e pouco engajados em questões educacionais mais amplas. Às vésperas da comemoração de 15 de Agosto, não havia nenhum tipo de informação sistematizada na mídia local sobre os motivos da comemoração estadual; nenhuma mobilização da sociedade civil na capital ou nos municípios do interior do Pará; nenhum projeto social ou cultural em voga nos

2 A pesquisa escolar foi realizada entre os dias 14 e 18 de agosto de 2018, em todas as turmas de $2^{\circ}$ e $3^{\circ}$ anos do Ensino Médio da Escola Estadual de Ensino Médio Prof. Antônio Gondim Lins, localizada no bairro do Coqueiro, município de Ananindeua-PA. 
órgãos de governo nas áreas de Educação e Cultura; nada de palestras, encontros, mostras nas universidades e centros superiores de ensino. Nenhuma referência significativa à vista, exceto o contentamento geral pela suspensão dos expedientes nas repartições públicas, sobretudo entre os servidores estaduais e municipais.

Afinal de contas, faz tempo que tem se desenvolvido uma visão bastante crítica sobre uma formação histórica escolar voltada para a exaltação de efemérides nacionais estabelecidas pelo Estado (BITTENCOURT, 2008, p. 57-67; PINSKY, 2011, p. 11-26). Desde, pelo menos, o fim dos regimes autoritários e militares na América Latina, em geral, e no Brasil em particular, a Educação no Brasil sofreu uma inflexão importante e passou a seguir outras diretrizes de formação básica, para ser pensada e praticada fora desses referenciais ideológicos de controle e de disciplinarização social, voltados para a uniformização de pensamentos e comportamentos dos cidadãos, cujo aprendizado deveria levá-los a serem obedientes e respeitadores da moral cívica e nacionalista (GÓMEZ CARRASCO; MOLINA PUCHE, 2017). Por que os estudantes e profissionais da Educação deveriam conferir atenção e homenagem a uma data que valoriza um processo político vinculado ao Estado? Por que dar importância a uma data comemorativa que somente relembraria um sistema público de ensino normalizador, baseado na hierarquia e obediência, o qual todos concordaram em erradicar e que não querem que retorne?

Em contrapartida a essa postura crítica em relação ao passado, colocamos outras provocações: será que comemorar a Adesão do Pará à Independência do Brasil, ou qualquer outra data histórica de caráter patriótico, na sociedade e na Escola, significa voltar aos parâmetros educacionais de governos autoritários? As comemorações regionais não teriam outras funções sociais, culturais e educacionais importantes, que não unicamente o controle social e/ou a exaltação do Estado? Em que medida a produção desses desconstrutivismos históricos na Escola contribui para uma espécie de "fratura" da construção da identidade nacional, a partir e referenciais regionais e locais? Essas questões parecem ser relevantes, sobretudo nos tempos atuais, nos quais os processos de ensino e aprendizagem escolar estão circunscritos a uma cultura global, frágil e líquida, marcada pelo desengajamento, descontinuidade, esquecimento e, por conseguinte, pela erosão dos conhecimentos culturais da nacionalidade e da 
regionalidade (SÁNCHEZ GAMBOA, 2001). De certa maneira, ainda vivemos uma experiência histórica marcada pelo transnacionalismo e pelo multiculturalismo, desde o fim da Segunda Guerra Mundial, que tem influenciado significativamente a questão identitária nos Estados nacionais (BAUMAN, 2013; MANN, 2000).

Este texto defende o argumento de que a abordagem escolar sobre as comemorações nacionais continua a ser importante referência de organização temporal e de compreensão do passado/presente social e de construção da identidade coletiva em diversos níveis de construção e de apropriação (BARTRA, 2000; LAVILLE, 1999). Festejos nacionais são marcos coletivos de tempo, "lugares de memória", com potencial significativo para educar crianças e jovens, que precisam ser reconhecidos e considerados no processo formal de construção da cidadania no regime democrático, sobretudo quando relacionados aos âmbitos regionais e locais (LOWENTHAL, 1998; NORA, 1993; SARLO, 2012). Desmemoriar marcos históricos importantes no processo educativo pode representar mais uma perda de construção de significados em relação ao passado e ao mundo em que vivemos, levando ao despertencimento identitário e à perda de oportunidades de instrumentalizar o conhecimento histórico em uma prática formativa que reforce a densidade democrática no cotidiano e no processo de ensino-aprendizagem dentro e fora da escola.

Desconsiderar essa memória regional e local no ambiente escolar, mesmo esta sendo investida de homenagem oficial, pode acentuar o papel dispersivo de um relativismo cultural, que tem fortalecido uma formação técnica voltada quase que exclusivamente para o mercado de trabalho e colocar em xeque a função do ensino de História nestes tempos complexos de globalização e de escalada mundial do neoconservadorismo de direita. Ao invés de educar a partir do conhecimento do passado/presente, estaríamos reforçando o esvaziamento de uma consciência histórica ${ }^{3}$ sobre as comemorações de cunho nacional, rejeitando oportunidades de construir concepções de identidade mais ajustadas aos fundamentos da Democracia. Essa ausência de orientação tem levado a uma espécie de não-lugar, progressivamente ocupado ora pelas opiniões dispersas e sem fundamentação,

3 Compreendemos "consciência histórica" como o processo de apropriação significativa, pelo alunado, do conhecimento histórico em geral, e dessa data magna em particular, a partir da qual o tempo presente ganha sentido, a partir da ampliação do conhecimento sobre o passado, e ainda influencia expectativas de futuro (CERRI, 2011; RÜSEN, 2007). 
registradas e compartilhadas nas redes sociais e nos aplicativos de mensagens eletrônicas, ora por uma ideologia hostil, violenta e "rizomática" aos princípios da Democracia (DELEUZE; GUATTARI, 1997), entendida como um igualitarismo pervertido e abstrato - que valorizaria a leniência, a dependência, o consumo de drogas, o crime, a pornografia, o sexo, etc. -, e que supostamente teria usurpado os lugares "naturais" da família, da igreja e da comunidade (ALMEIDA, 2018; ARAÚJO, 2008; CHAUÍ, 2006; GREEN, 2017; HUNTINGTON, 1999).

A abordagem sobre a comemoração do Dia 15 de Agosto pretende trazer à tona uma questão de fundo para reflexão: existe, ainda, alguma função social em ensinar a História, no regime democrático, a partir da memória estabelecida pelo Estado? Baseado em uma ampla pesquisa entre os diversos agentes de uma escola específica, este texto busca se distanciar de questões e problemas imediatos do processo de ensino e aprendizagem, geralmente voltados para uma adoção pragmática, imediatista e pouco crítica da investigação no cotidiano escolar, para dar ênfase ao tipo de tratamento que a memória histórica e a identidade nacional têm tido, sobretudo a partir do conhecimento histórico (ANDRÉ, 2001).

Assim, procuraremos desenvolver a nossa reflexão ao longo do texto a partir de uma contextualização histórica mais ampla das comemorações nacionais, tendo como foco a instituição da data magna de 15 de Agosto no Pará, na década de 1990; discutiremos, também, dentro de uma perspectiva histórica, as reformas educacionais nesse mesmo período, com foco nas leis e diretrizes sobre o ensino/aprendizagem de História no ensino médio; e, finalmente, partiremos para discutir os dados coletados na pesquisa escolar, desenvolvida na Escola Estadual de Ensino Médio "Prof. Antônio Gondim Lins", na periferia do município de Ananindeua, região metropolitana da cidade de Belém do Pará, e fazer uma análise das questões educativas e educacionais enfrentadas atualmente pela disciplina História, sobre a complexa relação entre a Nação, a região e o lugar, nos processos de construção da memória histórica e da identidade nacional.

\section{15 de Agosto: identidade nacional e globalização.}


Como qualquer outra comemoração oficial, a data magna de 15 de Agosto, referente à celebração pública e oficial da "Adesão do Pará à Independência do Brasil", foi instituída pelo Estado brasileiro. A demanda pela definição das datas magnas emergiu no Congresso Nacional a partir da necessidade de fixar os feriados civis a partir da homenagem às tradições históricas dos Estados da Federação, revogando, assim, uma antiga Lei de 1949, que somente considerava os chamados "dias santos" como festejos regionais, sendo a deliberação sobre os dias leigos de guarda atribuída somente ao Governo Federal (BRASIL, 1949a, art. 11) ${ }^{4}$. A Lei No 9.093, de 12 de Setembro de 1995, operou uma mudança nessa lógica, ao delegar às Assembleias Legislativas estaduais a atribuição de eleger a data magna local, que deveria ser celebrada segundo as tradições históricas de importância nos Estados, ao invés de continuarem celebrando datas históricas nacionais, desenraizadas do lugar (BRASIL, 1995) ${ }^{5}$.

A necessidade de construir referências cívicas nos estados da Federação fez parte de um projeto político mais amplo de reforçar a laicização do Estado nacional, a partir das comemorações locais. Seguramente por esse motivo é que na mesma Lei 9.093 foi sancionada a redução do número máximo de dias de guarda religiosos, que não poderia ser superior à quatro (com a inclusão da Sexta-Feira da Paixão), e instituiu as datas de fundação e centenários de fundação dos municípios como celebração obrigatória, sendo essas definidas pelas Câmaras locais. Essas disposições legais de incremento de datas cívicas locais e regionais estavam perfeitamente relacionadas às estratégias mais amplas do Estado brasileiro para redimensionar pedagogicamente a preservação da cultural nacional, especialmente no que esta tinha de contribuição para o reforço dos vínculos identitários (BRASIL, 1995) ${ }^{6}$.

Essa valorização das tradições locais foi fruto de um momento político e cultural renovado no Brasil e no mundo, oriundo de um processo de globalização

\footnotetext{
4De acordo com a referida Lei: "Art. $11^{\circ}$ : São feriados civis os declarados em lei federal. São feriados religiosos os dias de guarda, declarados em lei municipal, de acordo com a tradição local e em número não superior a sete."

5Segundo a Lei $\mathrm{N}^{\circ}$ 662, eram considerados feriados nacionais com data fixa: Confraternização Universal (1 de Janeiro); Tiradentes (21 de Abril); Dia do Trabalho (1 de Maio); Dia da Independência do Brasil ( 7 de Setembro); Dia da Padroeira do Brasil (12 de Outubro); Dia de Finados ( 2 de Novembro); Proclamação da República (15 de Novembro); e Natal (25 de Dezembro) (BRASIL, 1949b).

6Art. I, inciso III: "os dias do início e do término do ano do centenário de fundação do Município, fixados em lei municipal". Esse inciso foi incluído pela Lei n 9.335, de 10.12.1996 (BRASIL, 1996).
} 
e de crise, no qual os Estados nacionais tiveram que lidar com novas configurações sociais e culturais da modernidade, na última década e meia do século XX (COX, 1981; SANFELICE, 2001; SCHERER-WARREN, 1993). A conservação do papel regulador das instituições modernas, e, por conseguinte, da cultura, da memória e da identidade social, passaram a ser imperativos diante do avanço de um multiculturalismo mundializado e descentrado das tradições nacionais, oriundo do rápido desenvolvimento de novos sistemas globais de comunicação eletrônica, sobretudo das redes massificadas de imprensa escrita e televisiva. Nessa ordem pós-tradicional, aspectos da vida social de lugares e culturas distantes passam a fazer parte do cotidiano nacional, influenciando diretamente a autoidentidade de grupos e indivíduos, dentro de um quadro ampliado, mundial, fortemente marcado por novas formas de fragmentação e dispersão entre as dinâmicas do local e do global. O progressivo desenvolvimento das tecnologias e o seu impacto crescente como referência mediadora das relações sociais tem dado o tom da nova face do capitalismo "pós-moderno", e fortalecido "estilos de vida" pouco afeitos às narrativas genealógicas do passado, tradicionalmente circunscritas à pedagogia nacionalista. É a "retribalização" multicultural, a que se referia o filósofo Herbert McLuhan em trabalho seminal sobre o tema, que nos fragmenta no plano identitário para nos reunir em uma "aldeia global", que se estende às primeiras décadas do século XXI, com o protagonismo do computador, da internet e do smartphone (BAUMAN, 2005; BERMAN, 1986; GIDDENS, 2002; MCLUHAN; POWERS, 1993).

Como reforço a esses mecanismos de desencaixe, não há como não pensarmos as políticas oficiais das comemorações nacionais no Brasil sem atinar com as novas diretrizes que o processo de redemocratização brasileira passou a impor ao Estado nacional, em seus diversos níveis de poder. As décadas de 1980 e 1990 foram emblemáticas acerca da ação de uma nova sociedade civil organizada, composta por novos sujeitos coletivos, que adentraram a cena política (DOIMO, 1995; SADER, 1988; TELES, 2017). Em oposição ao que classificavam como Ditadura Militar - em referência ao Regime Civil-Militar que vigorou no Brasil entre 1964 e 1985 -, esses grupos sociais passaram a desenvolver uma forte atividade política em um ambiente de liberdade de expressão, em nível local, no campo e nas grandes cidades, sobre questões até então silenciadas: saúde e 
saneamento básicos; casa própria; meio ambiente e ecologia; acesso à terra, emprego e renda; direitos trabalhistas; direitos das minorias; dentre outras. No caso específico do Pará, merecem destaque os protestos de estudantes e profissionais da Educação em defesa da rede pública e gratuita de ensino, em Belém, e o assassinato de dezenove trabalhadores rurais do Movimento Sem Terra (MST) em Eldorado dos Carajás, na região sudeste do Estado, ambos acontecidos no mês de abril de 1996 (EVENTOS..., 2016).

Diante desses dois processos centrífugos, a globalização e a redemocratização, emergiram novas demandas oficiais pela manutenção da identidade coletiva. As múltiplas identidades construídas pelos grupos sociais precisavam de maior organicidade local, que pudessem convergir para referenciais mais abrangentes de nação e nacionalidade, normatizadas pelo Estado. Perante uma possível fragmentação dos signos comunitários nacionais de pertencimento, a partir da construção de novos processos de autoidentificação dos grupos e movimentos sociais, nos âmbitos global e local, as diferentes esferas de poder articularam uma estratégia de formação pública voltada para a valorização das identidades regionais e locais, que deveriam ressignificar o sentimento de pertença em relação à nação, começando pelo engrandecimento das tradições e processos históricos singulares das e nas unidades federativas da República. É nesse sentido que a eleição de datas magnas em todos os Estados brasileiros, comemorativas da identidade particular do "ser paulista", "ser gaúcho", "ser pernambucano" e, por conseguinte, do "ser paraense", deveriam contribuir para o fortalecimento e a conservação da Identidade Nacional, lastreada pela recuperação da narrativa genealógica do passado comum. Uma política cultural baseada no moderno discurso da inovação, mas com um profundo sentido de preservação da tradição histórica da Nação; ou, seguindo as palavras de Mona Ozouf (1977, p. 45), em importante estudo sobre a função dos festejos nacionais durante a Revolução Francesa (1789-1799), uma tentativa de "colocar em evidência uma dramatização da unidade".

"Dramatizar a unidade", desse modo, representava evitar o processo de desmonte do Estado e a corrosão da cultura nacional, em prol de uma nova/velha estratégia teatralizada de fabricação da memória e da identidade, baseado no que Benedict Anderson (2008) chamou de comunidade imaginada. Nessa linha é que, 
em 1996, foi proposto, na Assembleia Legislativa, o Projeto de Lei referente à adoção do dia 15 de Agosto como data magna de todo o extenso Estado do Pará. De autoria do jurista e então deputado estadual Zeno Veloso, a escolha do "dia da adesão à Independência, o que ocorreu em 1823" se deu "por ser um acontecimento decisivo, histórico, marcante e fundamental para a vida e para a história do Estado do Pará, que definiu seus rumos políticos desde então" (BOGEA, 2016 , p. [1]). A proposta de comemorar uma efeméride histórica como a integração da antiga Província do Pará ao então difuso território do Império do Brasil estava, claramente, dentro desse objetivo mais amplo do Estado nacional de constituir novos padrões de imaginação educacional, que estava sob o perigo da fragmentação política e cultural do multiculturalismo e do relativismo do mundo globalizado, assim como das múltiplas identidade oriundas do ativismo político dos novos grupos sociais de meados do século XX. Em outras palavras, o que se queria era restaurar conscientemente os antigos padrões de produção dos laços identitários da comunidade nacional, a partir de referenciais cronológicos mais horizontalizados de camaradagem local entre os diferentes agentes sociais, oriundos de grupos sociais, lugares e regiões muito diversas (ANDERSON, 2008; SANFELICE, 2001, p. 22-30).

Desse modo, seguindo a diretriz Federal, a Assembleia Legislativa do Estado do Pará sancionou a Lei № 5.999, de 10 de Setembro de 1996, na qual declarou o dia 15 de Agosto como Data Magna do Pará, revogando outros feriados estaduais. No mesmo texto legal, em seu Art. $2^{\circ}$, não foram deixadas dúvidas acerca da necessidade de comemoração do referido dia: "Os poderes do Estado tomarão providências para que a aludida data magna do Pará seja condignamente comemorada" (PARÁ, 1996, art. 2). A festa é um poderoso recurso simbólico de conservação da memória individual e coletiva; faz parte de um processo de delimitação temporal, em ordem cronológica, dos acontecimentos mais importantes do passado comum, e, portanto, da identificação a uma genealogia comunitária (OZOUF, 1974). Festejar a Adesão à Independência deveria representar a retomada da identidade local a partir de um acontecimento fundante do Estado-Nação, em um dos territórios mais ermos e periféricos do país, claramente compreendido como uma grande fronteira nacional. E não era qualquer acontecimento. Estamos falando do 15 de Agosto de 1823, marco de origem do 
Estado brasileiro no extremo norte da América do Sul, uma região historicamente bastante integrada às rotas e circuitos intracontinentais e caribenhos, distante culturalmente do Brasil, que tinha como centros o Rio de Janeiro, Recife e São Paulo (BRITO, 2008).

Para o jurista Zeno Veloso, o acontecimento que definiu a entrada do Pará na Nação brasileira deveria ter um melhor tratamento por parte das instituições públicas: "Muita gente nem sabe o porquê do feriado, mas deve atentar para a importância dessa data. Espero que um dia essa consciência exista no coração de todo cidadão paraense" (BOGEA, 2016, p. [1]). Como "lugar de memória", a data magna de 15 de Agosto deveria emitir signos de laços de pertencimento ao Pará e ao Brasil, sobretudo nas escolas da rede pública de ensino básico, mantendo a tradição de o conhecimento histórico escolar estar sempre a serviço da manutenção da identidade nacional através da tradicional pedagogia do cidadão. Daí a preocupação com a celebração anual dessa data magna, que deveria se dar através de solenidades cívicas, eventos comemorativos e ações educativas e culturais, que rememorassem a origem do Pará independente. Contra os mecanismos culturais e sociais de dispersão e fragmentação, externos e internos, o Estado moderno procurava recuperar elementos fundantes da nacionalidade no Pará, a partir do tradicional recurso à formação pedagógica da identidade no "coração" dos cidadãos de modo geral (FONSECA, 2003, p. 15-28; FONSECA, 2004; NADAI, 2011).

Reconhecer a importância da data magna do Estado do Pará deveria remeter diretamente à preservação desse lugar de memória, dessa tradição praticamente ausente do cotidiano social, pelas instituições governamentais, sobretudo pela rede pública de ensino. Daí o papel das leis para assegurar a conservação de fatos e processos históricos no coração do povo. A "consciência histórica", de que fala o jurista e autor do referido Projeto de Lei, não brotaria espontaneamente de uma suposta alma popular. Muito pelo contrário, inculcar qualquer tradição em uma comunidade exige, primeiramente, incorporá-la na formação escolar, também através das comemorações, tomadas como práticas didático-pedagógicas.

O período situado entre as últimas duas décadas do século $X X$ e as primeiras do século XXI foi particularmente propício às reformas na Educação nacional, que tinham como objetivo mais amplo adequar a formação básica ao recém-instituído 
regime democrático. Será que as questões relativas à preservação da cultura e da identidade nacionais estiveram presentes nessas reformas?

\section{Identidade nacional e as novas diretrizes educacionais.}

Praticamente todos os trabalhos recentes em Ensino de História que têm se dedicado ao estudo dos impactos da redemocratização brasileira sobre a Educação Nacional destacaram a necessidade sistêmica de renovação dos processos formativos escolares (FONSECA, 2003, p. 29-38; FONSECA, 2004, p. 67-71; BITTENCOURT, 2008; SOARES, 2002). Na esteira da promulgação da Constituição Federal de 1988, a estrutura educacional passou a estar atrelada às bases do Estado Democrático de Direito - a soberania, a cidadania, a dignidade da pessoa humana, os valores sociais do trabalho e da livre iniciativa, o pluralismo político , que acabaram fundamentando, em grande medida, as principais diretrizes da grande reforma educacional da década de 1990. Os profissionais da educação superior e básica envolvidos nessa mudança de paradigmas colocaram como imperativos a negação e a desconstrução do sistema educacional vigente durante o Regime Civil-Militar Brasileiro, cujas diretrizes estavam atreladas à Doutrina de Segurança Nacional e Desenvolvimento, na qual teve especial destaque um ensino voltado para a reprodução da ideologia oficial de controle moralizador e desenvolvimentista, destinado à obediência e disciplina de gestores, professores e alunos (MUNAKATA, 2000; SILVA; FONSECA, 2010).

Colocava-se como indiscutível a necessidade de purgar o recém-instituído regime democrático do "entulho autoritário". Ao invés da reprodução ideológica do progresso econômico desenvolvimentista e do culto ao patriotismo abstrato dos discursos, símbolos e heróis nacionais, o regime democrático da "Nova República" deveria ser fortalecido com novas bases de formação, mais afeitas ao que pregava o Estado na nova "Constituição Cidadã". Nesse sentido é que a primeira modificação de perspectiva, anterior à instituição da Lei de Diretrizes e Bases da Educação (LDB), pode ser realizada em redes de ensino público de alguns Estados, como foi o caso de Minas Gerais, cuja Secretaria de Educação passou a defender a introdução da análise social marxista nos materiais didáticos e currículos 
escolares, sobretudo os de História (MUNAKATA, 2000, p. 279-282). O que se queria era trazer à luz as diversas ações, presentes e passadas, dos grupos e classes sociais antes silenciadas e excluídas dos processos escolares de ensino e aprendizagem, principalmente nas disciplinas de História e Geografia, unificadas nos chamados "Estudos Sociais", e comprometidas com a ideologia transversal de culto ao civismo no sistema público de ensino, reforçadas pelas disciplinas Educação Moral e Cívica (Ensino Fundamental), Organização Social e Política do Brasil (Ensino Médio), e Estudos dos Problemas Brasileiros (Ensino Superior) (BRASIL, 1971) ${ }^{7}$.

Desconstruir. Esta parecia ser a palavra de ordem do estabelecimento da Democracia no sistema educacional brasileiro e, por conseguinte, de uma nova História escolar. A emergência do ativismo político dos grupos sociais trabalhadores rurais e urbanos, sem terras, mulheres, indígenas, negros, entre outros - passou a integrar uma concepção de sociedade pluralista, que deveria ser contemplada nos currículos escolares. Os Parâmetros Curriculares Nacionais de História (PCN's), publicados em 1996, são o produto de diversas experiências curriculares renovadoras, que vinham sendo desenvolvidas em diversas redes públicas de ensino básico, com o objetivo de proporcionar "uma transformação positiva no sistema educativo brasileiro", procurando, sobretudo, "respeitar diversidades regionais, culturais, políticas existentes no país, e [por outro lado], considerar a necessidade de construir referências nacionais comuns ao processo educativo em todas as regiões brasileiras" (BRASIL, 1998, p. 5) ${ }^{8}$. Os currículos voltados para o ensino/aprendizagem de História deveriam fortalecer essa concepção pluralista de sociedade, que tinha sido sufocada no regime civil-militar, na qual passara a ser inserida a própria escola pública, cuja base passou a ser reconhecida como socialmente diversa e heterogênea (BITTENCOURT, 2008; FONSECA, 2003, p. 29-38).

Ensino pluralista para uma nova educação democrática. Essa era a prioridade conferida ao ensino/aprendizagem de História desde a segunda metade

\footnotetext{
7 Estamos nos referindo principalmente ao Decreto-Lei $N^{\circ} 68.065$, de 14 de janeiro de 1971, que dispõe sobre a inclusão da Educação Moral e Cívica como disciplina obrigatória nas escolas de todos os graus e modalidades de ensino.

8Trechos retirados da mensagem "Ao Professor" do então Ministro da Educação e do Desporto, Paulo Renato de Souza.
} 
da década de 1980, que tem sido estendido até os dias de hoje. O ponto nevrálgico desse debate, para os objetivos desse texto, é que, no afã de valorizar os princípios pluralistas da nova Democracia política, a legislação educacional e o ensino de História acabaram por desconsiderar a importância fundamental da construção de uma identidade em nível nacional. Textualmente, é bastante clara a posição secundária que os sentimentos identitários nacionais ocupam, por exemplo, nos PCN's do Ensino Fundamental, nos quais, dentre os seus princípios transversais que procuram articular a dimensões do local, nacional e global, mas que existe uma ênfase mais centrada na construção de identidades locais, sem o devido reconhecimento da importância que o sentimento de nação entre as crianças.

Conhecer características fundamentais do Brasil nas dimensões sociais, materiais e culturais como meio para construir progressivamente a noção de identidade nacional e pessoal e o sentimento de pertinência ao país (BRASIL, 1998, p. 7).

Nos Parâmetros Curriculares Nacionais do Ensino Médio (PCNEM), publicados em 1999, esse sentimento de pertinência ao país/nação sequer figura nas competências e habilidades do ensino de História. O conhecimento histórico escolar, organizado curricularmente como parte das chamadas "humanidades e suas tecnologias" - compostas pelas disciplinas de História, Geografia, Filosofia e Sociologia -, deve preparar os/as adolescentes para os "desafios postos por uma sociedade tecnológica" e para a "a necessária superação dos 'anos de chumbo' da história recente do País, com todas as suas consequências nefastas para o convívio social e, em especial, para a educação" (BRASIL, 1999, p. 8). Superar o ensino ideológico do período civil-militar, praticamente anulou também a importância de se construir bases nacionais identitárias entre os jovens, que pudessem gerar uma valorização mais ampla dos bens culturais do presente/passado/futuro da nação, a partir das dimensões da região, da província e do lugar. O ensino de História deveria ser direcionado para o reconhecimento e construção de um pluralismo social e cultural a partir da diferença, que favorecesse um tipo de identidade mais afeita às competências do multiculturalismo globalizado, com sua velocidade temporal e suas metas de mercado; ou seja, consolidar uma formação tecnicista e pragmática mais direcionada para lidar com tempos de competitividade e de "revolução permanente" da sociedade pós-industrial (BAUMAN, 2013, p. 13-18). 
Desse modo, as diretrizes curriculares para o Ensino Médio abordaram a "atualização da educação escolar" como um processo de autorreconhecimento identitário, pessoal e social dos educandos. Os efeitos dessa desterritorialização nacional do saber histórico escolar logo se fizeram sentir na produção dos livros didáticos de História, cujas narrativas do presente/passado passaram a privilegiar padrões cosmopolitas de pensamento, comportamento e expectativas de futuro pouco afeitas às interações entre o global e o local. O debate sobre a forte e rápida emergência do multiculturalismo nos livros didáticos e nos "sistemas de ensino" tem mostrado facetas muito interessantes, que vão desde as produções narrativas excessivamente descritivas e descentradas de culturas e identidades variadas, até os interesses materiais de grandes organismos financeiros globais - Fundo Monetário Internacional, Banco Mundial, Banco Interamericano de Desenvolvimento, etc. - e sua influência crescente nos sistemas educacionais de vários países, que direcionam as competências curriculares para a preparação técnica e ideológica do mercado de trabalho tecnológico e mundializado (AVELAR; BALL, 2017). O forte direcionamento dos livros e materiais didáticos em direção uma representação do conhecimento histórico a partir de uma matriz curricular cosmopolita tem aprofundado a distância atual entre a legislação educacional relativa ao currículo de História e os currículos efetivos ensinados nas salas de aula (CASSIANO, 2017; RAMOS, 2007).

Ao considerar que a sala de aula possui clara autonomia de apropriação e construção do conhecimento histórico a partir da cultura escolar e das experiências sociais, não é possível negar que os conteúdos de História efetivamente ensinados no Ensino Médio estão cada vez mais ajustados conceitualmente às diretrizes curriculares institucionalizadas, ligadas aos princípios de eficiência, concorrência e busca de resultados. Vários autores têm demonstrado empiricamente que a formação histórica escolar tem tido uma progressiva influência de processos seletivos vestibulares e, mais recentemente, o Exame Nacional do Ensino Médio (ENEM). De fato, o seletivo para o ensino superior, instituído também na década de 1990, tem ditado um ensino/aprendizagem de História pouco atrelado à formação básica que os jovens necessitam, estando mais relacionado aos princípios de competitividade do certame pré-universitário, o que tem levado à diluição do processo educacional contido nos PCNEM. O Ensino Médio brasileiro 
tem sido um grande curso preparatório, para o qual as redes de ensino públicas têm se organizado, em busca de índices de aprovação, encarados como sinônimos de qualidade de ensino e de direcionamento para uma educação tecnicista, pragmática e conteudista (CERRI, 2004; MAGALHÃES, 2006; SOARES, 2002).

O currículo efetivo tem determinado os rumos do ensino de História no cotidiano das salas de aula das redes públicas e tem impactado os professores e sua liberdade de ensinar, gerando um crescente desmemoriamento acerca das referências identitárias nacionais. Isso foi particularmente sintomático na pesquisa com docentes sobre o esquecimento escolar sobre a data magna da Adesão do Pará à Independência do Brasil. Ao ser questionado sobre os motivos desse esquecimento coletivo entre os/as alunos/as da E.E.E.M. Prof. Antônio Gondim Lins, o professor de História, respondeu nesses termos:

[...] Pouco se trabalha, ou se dá a ênfase que se deveria, a este acontecimento [Adesão do Pará à Independência do Brasil] de suma importância na História do Pará. Mas, não é que os professores [...] a gente até tenta $[\ldots]$ Às vezes não $[\ldots]$ nem sempre $[. .$.$] realmente$ [...]. Talvez, não se dá ênfase, [porque] às vezes o próprio sistema também não alavanca muito, né? Se a gente for ver como que a escola tem o propósito de estar realmente com o ENEM, o ENEM não dá ênfase nessas revoltas. [...]. Quando se tinha o sistema de vestibulares locais, a gente via mais [esses conteúdos] do que no ENEM. ${ }^{9}$

Existe uma consciência histórica docente que indica um crescente desmemoriamento do passado nacional, e, por conseguinte, regional e local, nos currículos de História ensinados na escola. Esse dado não está restrito à realidade da escola pública na Amazônia. Além disso, não existe nenhuma diretriz curricular no ensino de História que provoque uma discussão acerca da importância de construção do sentimento de pertinência à nação na formação básica de crianças e, principalmente, dos jovens brasileiros. A legislação educacional brasileira que emergiu com a "Nova República" tem negligenciado uma formação identitária atrelada à cultura histórica escolar, isto é, à construção do conhecimento histórico significativo e voltado para a vida social, em prol de um ensino que tem pulverizado o processo de construção de um sentimento mínimo de nacionalidade no Brasil do

9Entrevista com o professor de História A.M., realizada em novembro de 2018. 
século XXI (GABRIEL, 2015; SCHIMIDT, 2012). Isso tem tido importantes implicações políticas e sociais, como as divisões identitárias regionais e locais, fruto dos afastamentos centro-periferia e campo-cidade, e seu leque cada vez mais diversificado de discriminações sociais, políticas, etnicorraciais, de gênero, que têm sido fortemente capitaneadas por correntes neoconservadoras de direita, com um sentido identitário nacional ideologicamente centrado na cultura política do longo passado ditatorial brasileiro (GREEN, 2016; NAPOLITANO; RIBEIRO, 2017).

\section{Democracia e ensino de História: elementos empíricos e perspectivas.}

A pesquisa empreendida na Escola Estadual de Ensino Médio Prof. Antônio Gondim Lins - ligada ao Projeto de Pesquisa Adesão do Pará à Independência: memória e ensino de História -, trouxe resultados bastante significativos sobre processos de desmemoriamento da cultura nacional entre os/as adolescentes e jovens adultos do Ensino Médio, que nos permite dimensionar o estado da fratura identitária vivenciada na escola pública. Com o objetivo de construir um diagnóstico sobre o (des)conhecimento acerca da data magna paraense de 15 de Agosto, foram passados questionários para todas as turmas dos $2^{\circ}$ e $3^{\circ}$ Anos do Ensino Médio, totalizando 597 estudantes, dos turnos da manhã e tarde, (Tabelas 1 e 2). O impacto quantitativo da pesquisa-questionário demonstra uma alta participação dos/as discentes do turno da manhã, superando os 75\%; enquanto o alunado matriculado no turno da tarde, ao contrário, não atingiu nem os 50\%, o que aponta para o progressivo problema da evasão que a escola tem enfrentado no turno vespertino, ao longo dos últimos 10 anos $^{10}$.

\section{Tabela 1 - Impacto escolar da pesquisa (turno matutino)}

$\begin{array}{lccc}\text { Série } & \begin{array}{c}\text { Discentes } \\ \text { Matriculados }\end{array} & \begin{array}{c}\text { Discentes } \\ \text { Participantes }\end{array} & \text { Participação (\%) } \\ \mathbf{2}^{\mathbf{0}} \text { Ano } & 188 & 158 & 84,04 \% \\ \mathbf{3}^{\circ} \text { Ano } & 150 & 101 & 67,33 \% \\ \text { Total } & 338 & 259 & 76,62 \%\end{array}$

Fonte: Oeiras (2018, p. 3).

10Entrevista com a Gestora Escolar, Profa. B.B. realizada em novembro de 2018. 


\section{Tabela 2 - Impacto escolar da pesquisa (turno vespertino)}

$\begin{array}{lccc}\text { Série } & \begin{array}{c}\text { Discentes } \\ \text { Matriculados }\end{array} & \begin{array}{c}\text { Discentes } \\ \text { Participantes }\end{array} & \text { Participação (\%) } \\ \mathbf{2}^{\mathbf{0}} \text { Ano } & 66 & 37 & 56,06 \% \\ \mathbf{3}^{\circ} \text { Ano } & 58 & 22 & 37,93 \% \\ \text { Total } & 124 & 59 & 47,58 \%\end{array}$

Fonte: Oeiras (2018, p. 4).

Os dados acima também proporcionaram um diagnóstico bastante interessante sobre a cultura escolar dos/as estudantes, relacionada aos significados das comemorações estaduais/nacionais e, em particular, da importância data magna da Adesão do Pará à Independência. Nesse sentido, o corpo do questionário foi composto por três perguntas-chaves: 1) Você sabe por que o dia 15 de Agosto é feriado em todo o Estado do Pará? 2) Você lembra se o fato histórico acontecido em 15 de Agosto foi ensinado alguma vez na sala de aula? 3) Você lembra se houve alguma atividade (trabalho, apresentação artística, roda de conversa, etc.) relacionada ao dia 15 de Agosto na Escola? As três perguntas vinham acompanhadas das alternativas "Sim", "Não" e "Não tenho certeza", com espaços para justificativas pontuais. Os resultados da enquete mostram que, tomando em conta dados totais, aproximadamente $65 \%$ do corpo discente que estava presente no dia da aplicação da pesquisa não conseguiu identificar minimamente o porquê de se comemorar do dia 15 de Agosto, ou seja, não conseguiram significar historicamente a data magna da "Adesão do Pará à Independência do Brasil". Por outro lado, cerca de 35\% dos/as estudantes conseguiram fazer a referida identificação de forma muito básica, claramente desvinculada do conhecimento histórico escolar, sem conseguir desenvolver a relação presente/passado (Tabela 3 ).

\section{Tabela 3 - Conhecimento escolar sobre a data magna}

\begin{tabular}{l|cc|c|} 
& $\begin{array}{c}\text { Identificaram a } \\
\text { Data Histórica }\end{array}$ & $\begin{array}{c}\text { Não identificaram/ } \\
\text { Relacionaram a outros Eventos }\end{array}$ & Não responderam \\
\hline $\mathbf{2}^{\circ}$ Ano & $26,5 \%$ & $24,5 \%$ & $49 \%$ \\
\hline $\begin{array}{l}\mathbf{3}^{\circ} \\
\text { Ano }\end{array}$ & $44,3 \%$ & $15,9 \%$ & $39,8 \%$ \\
Média & $35,4 \%$ & $20,2 \%$ & $44,4 \%$ \\
\hline
\end{tabular}


Fonte: Oeiras (2018, p. 3-4).

Apesar das inevitáveis imprecisões e possíveis "vácuos" existentes em qualquer análise quantitativa de dados oriundos da subjetividade, os mesmos sugerem claramente que o ensino de História, especificamente no Ensino Médio, não tem abordado e/ou discutido as comemorações oficiais na sala de aula. Uma pequena parte dos/as estudantes respondeu que teve contato com informações acerca do processo histórico da "Adesão" por meios variados, o que denota a existência de entrecruzamentos de saberes entre a escola e a comunidade - ou entre a cultura escolar e a cultura histórica - que, pelo visto, não estão sendo devidamente trabalhados no ensino de História: escola (21), televisão (5), internet (4), amigos e familiares (6) ${ }^{11}$. Esses dados mostram pouquíssimo das lógicas pelas quais o conhecimento histórico regional é construído pelos jovens do Ensino Médio, o que tem nos feito redirecionar a metodologia de trabalho para a pesquisa-ação escolar e para a produção de etnografias docentes e discentes; apontam, no entanto, para a pouca (ou quase nula) atuação da escola e do ensino de História com temas educacionais relacionados à memória nacional e às interrelações possíveis com as dinâmicas de aprendizagem significativa a partir da memória coletiva, que sirvam para a construção de identidades regionais e locais, que também estão presentes na vida social.

Vida social, com suas dificuldades cotidianas, que pulsa no cotidiano e na cultura escolar de estudantes e professores. A Escola Estadual de Ensino Médio Prof. Antônio Gondim Lins, uma das maiores e mais tradicionais instituições de ensino público do município de Ananindeua, atende a um público de aproximadamente 2.000 alunos/as, nos três turnos letivos (manhã, tarde e noite), proveniente de três grandes periferias: os bairros do Coqueiro, PAAR e Curuçambá. Essas três grandes periferias urbanas, que concentram cerca de $70 \%$ da população de Ananindeua, têm enfrentado graves problemas sociais nas últimas duas décadas, sobretudo relacionados aos altos índices de desemprego, vulnerabilidade econômica, criminalidade e violência, somados aos baixos índices de emprego

11Relatório Técnico-Científico do Plano de Trabalho "Adesão do Pará à Independência: significados de uma efeméride no espaço escolar", desenvolvido pelo bolsista PIBICEnsino Médio José Matheus da Costa Oeiras. 
formal, saneamento básico e qualidade de vida (IBGE, 2016)12. Todos esses problemas sociais, juntamente com constantes denúncias de precarização e abandono da infraestrutura escolar pública pelo Governo do Estado, têm sido amplamente divulgados na imprensa escrita e televisiva, além dos sítios virtuais de internet e nos aplicativos de mensagens instantâneas, com inserção direta na comunidade escolar. Em uma entrevista veiculada publicada na imprensa televisiva local, um professor da escola chegou a afirmar que "isso [falta de infraestrutura e segurança] influencia diretamente na relação ensino/aprendizagem. Já tivemos vários professores assaltados, não somente aqui, mas também em outras escolas. Isso é uma práxis, infelizmente...". Professores e estudantes têm tornado públicas as grandes dificuldades que a escola tem enfrentado (ALUNOS..., 2018; ESTUDANTES..., 2015; PROTESTO..., 2017).

As experiências socioescolares compartilhadas pelos agentes da E.E.E.M. Prof. Antônio Gondim Lins - marcadas por crescentes mobilizações, protestos e ocupações das salas de aula- poderiam servir de base para outras abordagens sobre a data magna de 15 de Agosto. O clima político intenso no interior da escola, sobretudo com a articulação entre o Grêmio Estudantil e alguns professores, tem criado oportunidades importantes para discutir questões fundamentais que remontam à historicidade das formas de organização social e política das pessoas comuns em importantes processos históricos do passado. A Base Nacional Comum Curricular para o Ensino Médio (BNCC), publicada oficialmente em dezembro de 2017, abre possibilidades de se trabalhar com duas importantes competências das "Ciências Humanas e Sociais Aplicadas no Ensino Médio", que direcionam o ensino e a aprendizagem para a interrelação entre processos políticos e sociais em diferentes temporalidades e a construção consciente da cidadania e do respeito ao pluralismo democrático:

12Segundo o último levantamento estatístico publicado pelo Instituto Brasileiro de Geografia e Estatística (IBGE), em 2016, o município de Ananindeua possui um índice de população formal ocupada de apenas $13 \%$, ou seja, cerca de 66.269 pessoas, de uma população de 471.980 habitantes; esse montante formalmente empregado no mercado de trabalho possui uma renda média de 1,9 salários mínimos. Outros dados alarmantes são relativos ao território e ambiente, os quais indicam uma superfície de $55,1 \%$ de área com esgotamento sanitário adequado, $10,5 \%$ de arborização pública e $24 \%$ das vias urbanas devidamente asfaltadas e estruturadas, de uma área territorial de $190.451 \mathrm{~km}^{2}$ (IBGE, 2016).

História \& Ensino, Londrina, v. 27, n. 1, p. 93-122, jan./jun. 2021 
Competência Específica 1: Analisar processos políticos, econômicos, sociais, ambientais e culturais nos âmbitos local, regional, nacional e mundial em diferentes tempos, a partir de procedimentos epistemológicos e científicos, de modo a compreender e posicionar-se criticamente com relação a esses processos e às possíveis relações entre eles.

Competência Específica 6: Participar, pessoal e coletivamente, do debate público de forma consciente e qualificada, respeitando diferentes posições, com vistas a possibilitar escolhas alinhadas ao exercício da cidadania e ao seu projeto de vida, com liberdade, autonomia, consciência crítica e responsabilidade (BRASIL, 2017, p. 559-565).

As recentes experiências fabricadas coletivamente por estudantes e docentes na cultura escolar para a vivência política no ambiente democrático podem ser diretamente relacionadas, por outro lado, às novas abordagens historiográficas sobre o processo de Independência brasileira no Pará. O processo de emancipação política regional tem sido interpretado por historiadores locais, a partir de referenciais analíticos da história social e de uma nova história política, especialmente no sentido de desconstruir o "mito da adesão", cujo eixo explicativo concentra-se na clássica interpretação do processo de Independência como parte de um acordo vertical entre grupos dirigentes do Rio de Janeiro e de Belém (MUNIZ, 1973) ${ }^{13}$. Ao acompanhar as novas abordagens é possível construir outros ângulos interpretativos para a Independência brasileira no Pará, menos como um acordo "por cima" e mais como um campo mais ou menos horizontal de disputas políticas, que envolveram grupos dirigentes de diversas Câmaras municipais do interior da antiga província do Grão-Pará, assim como a participação e a construção de difusos projetos políticos e sociais a partir da imprensa difusora e das camadas "de baixo" daquela sociedade (BRITO, 2008; COELHO, 1993; MACHADO, 2006; SOUZA JUNIOR, 1997). Experiências e expectativas vivenciadas e construídas coletivamente em temporalidades do presente e do passado podem criar um ambiente propício a um ensino de História que reforce uma formação básica nos jovens das periferias voltada para o que Jörn Rüsen nomeou como

$13 \mathrm{~A}$ interpretação historiográfica da "Adesão do Pará à Independência" envolveu diretamente as comemorações do centenário da Independência brasileira no Pará, em 1923, nas quais teve um grande destaque uma edição comemorativa da Revista do Instituto Histórico e Geográfico do Pará (IHGP), organizada pelo então secretário João de Palma Muniz. A obra foi reeditada em formato fac-símile em 1973, nas comemorações do sesquicentenário da Adesão. 
"orientação", ou seja, um estado de consciência crítica socioescolar, que resultaria em usos do conhecimento histórico para a formação da identidade individual e coletiva, e para a práxis da vida social no presente, em direção ao futuro, de acordo com um conceito de cidadania plural, própria das democracias contemporâneas (RÜSEN, 2007).

Comemorar a data magna de 15 de Agosto, nesse sentido, teria relação com processos de ressignificação por parte de alunos e professores, que tirariam do lugar político e social a "Adesão", para dar-Ihes contornos críticos, mais adequados à realidade social e à Democracia brasileira. Ao invés de celebrar uma efeméride, um grande feito do passado, com o sentido de culto ao passado, o dia 15 de Agosto poderia ser reconstruído a partir do cotidiano multifacetado de lutas e acomodações dos integrantes da própria comunidade escolar "Prof. Antônio Gondim Lins"; no lugar de compreenderem um episódio da História regional, poderiam "desfigurar" o fato histórico, para entender a sua fabricação. Múltiplos sentidos constituem a realidade social. O ensino de História precisa dar conta de apresentar essa multiplicidade aos jovens brasileiros, para que possam relacionar presente, passado e futuro de forma mais lúcida, a partir de uma noção de sala de aula como espaço de construção do saber histórico na interface com diversos saberes e experiências socioescolares.

A ação humana na História jamais está limitada a um conjunto específico de sujeitos; a narrativa dessa ação é que tem sido socialmente circunscrita. Isso pode parecer assente para historiadores profissionais, mas não o é para professores e estudantes em contato com o conhecimento histórico formal, presente nos livros didáticos e paradidáticos de História. O ensino dessa ação histórica socialmente plural precisa adentrar as salas de aula, sobretudo do Ensino Médio, para contribuir com a formação de jovens prestes a entrar no mercado de trabalho e adquirir responsabilidades deliberativas sobre o sistema político. É necessário abordar as comemorações nacionais também para discutir e construir novos significados de identidade nacional, que perpasse a diversidade de regiões, culturas, formações históricas, religiosidades, gêneros e matrizes étnico-raciais que integram o continente-Brasil do século XXI. O ensino de História precisa estimular a fabricação identitária que envolva não somente a diferença, mas que construa um sentido de 
pertença oriundo do compartilhamento de um sentimento comum. Esse pertencimento, na nossa leitura, é a Democracia e os seus valores constituintes.

\section{Considerações Finais}

Abordar datas comemorativas como a da "Adesão do Pará à Independência" nas salas de aula do Ensino Médio precisa reforçar os valores, memórias, princípios, identidades e fundamentos da Democracia. Essa premissa se torna ainda mais realista em um momento no qual existe um sentimento de incerteza cada vez mais disseminado entre professores/as de História das redes públicas de ensino básico, verbalizado informalmente dentro e fora das escolas e das Universidades, relacionado ao futuro da educação no Brasil. A construção mínima de um sentimento de pertinência à nação brasileira parece ser fundamental, sobretudo por conta do avanço do multiculturalismo tecnológico globalizado, já bastante discutido ao longo do texto, mas também por conta do momento de crise do regime democrático nacional e de seus desdobramentos no cotidiano político e social da educação. Parece-nos pertinente discorremos um pouco sobre o atual momento neoconservador brasileiro, fonte de muitas angústias por parte de professores de História.

Desde as manifestações de rua pela melhoria e gratuidade do transporte público de junho de 2013 em São Paulo, protagonizadas pelo Movimento Passe Livre (MPL), foi estabelecia uma atmosfera de tensão social no país, amplificada por grande parte da mídia televisiva e pela internet, que tem fortalecido setores e ideias da extrema direita brasileira. Como uma espécie de tsunami, os posicionamentos extremistas de um suposto combate à corrupção e aos privilégios políticos de agentes governamentais do Partido dos Trabalhadores (PT) levaram a uma aceleração do tempo da política, que resultou no segundo processo de impeachment da história da "Nova República", realizado entre 2015 e 2016. De lá para cá, o panorama sociopolítico nacional tem sido fortemente caracterizado por práticas públicas e cotidianas de radicalismo e intolerância política, sobretudo de grupos alinhados aos posicionamentos de uma extrema direita neoconservadora, que tem se fortalecido nos círculos palacianos desde então, e que acabou obtendo 
êxito eleitoral com a vitória, em 2018, do Partido Social Liberal (PSL) (MATTOS; BESSONE; MAMIGONIAN, 2016).

Todo esse rápido processo de transformação na política brasileira tem sido acompanhado de perto pelos historiadores e outros profissionais da educação. Em diversas manifestações públicas, individuais e coletivas - como a realizada pela Associação Nacional dos Professores Universitários de História (ANPUH) - e de grupos organizados nas redes sociais - a exemplo do grupo "Historiadores pela Democracia", atuante no Facebook e em outras mídias sociais -, professores/as de História têm denunciado o impedimento da Presidente Dilma Rousseff (PT) como um processo ilegítimo, gerado a partir de uma articulação "por cima" entre o Congresso Nacional e o Poder Judiciário, cujo ápice foi o desferimento do golpe parlamentar de 2016 (MATTOS; BESSONE; MAMIGONIAN, 2016, p. 8-10). Essa situação, cujas consequências ainda perduram, tem levado a uma crise estrutural na política brasileira, com o enfraquecimento gradativo dos princípios da soberania popular, fundamento basilar da Democracia. Não é à toa que jornalistas e estudiosos especializados no estabelecimento da ditadura civil-militar no Brasil, em 1964, têm dado ênfase, na imprensa mundial, à escalada do autoritarismo e ao perigo de golpe de Estado que estaria a pairar sobre as instituições da República, com a ascensão do PSL ao Poder Executivo nas eleições de 2018 (NEVES, 2018; COELHO, 2018) ${ }^{14}$.

Nesses primeiros meses da nova gestão presidencial, as comemorações voltaram à cena política e social. Grupos conservadores têm colocado em evidência a necessidade de celebrar o dia 31 de Março de 1964, no qual foi iniciado o Regime Civil-Militar brasileiro a partir de um golpe de Estado, com um sentido de "revolução democrática", que teria afastado o país do comunismo. Essa inclinação presidencial, amplamente criticada por setores do próprio governo, tem chegado às escolas de formação básica, sobretudo àquelas que compartilham dos valores

\footnotetext{
14Duas matérias jornalísticas publicadas na grande imprensa brasileira tiveram particular repercussão. A primeira, uma entrevista com a historiadora francesa Maud Chirio, especialista em história da direita brasileira, que afirmou que a eleição de Jair Bolsonaro à Presidência marcaria o fim da "Nova República". A segunda, uma edição da coluna de Marcelo Coelho, que defendia que, após o atentado sofrido por Jair Bolsonaro em Juiz de Fora-MG, já existiria uma preparação arquitetada para a efetivação de um golpe de Estado, defendido internamente pelo círculo militar do PSL.
} 
cristãos, vinculadas ao neopentecostalismo. Estamos vivenciando o auge do neoconservadorismo da "Nova República".

Diante da possibilidade de que valores neoconservadores sejam defendidos e ensinados nas escolas públicas é que precisamos repensar e redimensionar o ensino de História. Um caminho que este estudo aponta é para o uso das experiências socioescolares nos estudos sobre as comemorações nacionais, a partir das realidades regionais e locais. Dito de outra maneira, precisamos reduzir as distâncias entre a cultura histórica e a cultura escolar nas aulas de História, para que a realidade social possa ser instrumentalizada como estratégia de ensino e aprendizagem do presente-passado da nação, da região e do lugar. Além disso, ensinar História precisa considerar teoricamente a construção plural de várias realidades sociais, nas quais todos nos inserimos, para que possamos discutir a fabricação historiográfica do passado comum. Desse modo, cumpriremos os objetivos da educação pública, edificada junto com os princípios da Democracia. Sem isso, continuaremos a construir um conhecimento de História amplamente desinteressante nas escolas, refém do desmemoriamento, e pouco significativo para a vida de crianças e jovens, que precisam, ao fim e ao cabo, aprender a historicidade e a complexidade do mundo em que todos vivemos.

\section{Referências}

ALMEIDA, Silvio Luis de. Neoconservadorismo e liberalismo. In: GALLEGO, Ester Solano (org.). O ódio como política: a reinvenção das direitas no Brasil. São Paulo: Boitempo, 2018, p. 23-28.

ALUNOS ocupam escola para cobrar manutenção em Ananindeua. Por Sancha Luna. Belém do Pará: RBATV Oficial, 2018. 1 vídeo (5min03). Disponível em: https://www.youtube.com/watch?v=0jAS-Ko_AlU. Acesso em: 21 fev. 2019.

ANDERSON, Benedict. Comunidades imaginadas: reflexões sobre a origem e a difusão do nacionalismo. São Paulo: Companhia das Letras, 2008.

ANDRÉ, Marli. Pesquisa em educação: buscando rigor e qualidade. Cadernos de Pesquisa, São Paulo, n. 113, p. 51-64, jul. 2001.

ARAúJO, Maria Celina de. Densidade democrática e instabilidade na redemocratização latino-americana. In: FICO, Carlos et al. (org.). Ditadura e democracia na América Latina: balanço histórico e perspectivas. Rio de Janeiro: Editora FGV, 2008. p. 321-338. 
AVELAR, Marina; BALL, Stephen J. Mapping new philanthropy and the heterarchical state: The Mobilization for the National Learning Standards in Brazil. International Journal of Educational Development, [London], p. 1-9, 2017. DOI: http://dx.doi.org/10.1016/j.ijedudev.2017.09.007. Acesso em: 21 fev. 2019.

BARTRA, Roger. A gaiola da melancolia: identidade e metamorfose do mexicano. Projeto História, São Paulo, v. 20, p. 23-33, abr. 2000.

BAUMAN, Zygmunt. Identidade: entrevista a Benedetto Vecchi. Rio de Janeiro: Zahar, 2005.

BAUMAN, Zygmunt. Sobre educação e juventude: conversas com Riccardo Mazzeo. Rio de Janeiro: Jorge Zahar Editor, 2013.

BERMAN, Marshall. Tudo que é sólido se desmancha no ar: a aventura da modernidade. São Paulo: Companhia das Letras, 1986.

BITTENCOURT, Circe. Ensino de história: fundamentos e métodos. 2. ed. São Paulo: Cortez, 2008.

BOGEA, Hiroshi. A adesão do Pará à independência é data magna do calendário cívico paraense. [S. I.], 15 ago. 2016. Disponível em: http://www.hiroshibogea.com.br/37023-2/. Acesso em: 7 out. 2018.

BRASIL. Câmara dos Deputados. Decreto-Lei No 68.065, de 14 de janeiro de 1971. Regulamenta o Decreto-lei no 869, de 12 de setembro de 1969, que dispõe sobre a inclusão da Educação Moral e Cívica como disciplina obrigatória, nas escolas de todos os graus e modalidades dos sistemas de ensino no País, e dá outras providências. Brasília: Câmara dos Deputados, 1971. Disponível em: http://www2.camara.leg.br/legin/fed/decret/1970-1979/decreto-68065-14janeiro-1971-409991-publicacaooriginal-1-pe.html. Acesso em: 24 out. 2018.

BRASIL. Lei no 605, de 5 de Janeiro de 1949. Repouso semanal remunerado e o pagamento de salário nos dias feriados civis e religiosos. Brasília: Presidência da República, 1949a. Disponível em: http://www.planalto.gov.br/CCivil_03/leis/L0605.htm\#art11. Acesso em: 6 out. 2018.

BRASIL. Lei $n^{\circ}$ 662, de 6 de Abril de 1949. Declara feriados nacionais os dias 10 de janeiro, 10 de maio, 7 de setembro, 15 de novembro e 25 de dezembro. Brasília: Presidência da República, 1949b. Disponível em: http://www.planalto.gov.br/ccivil_03/leis/I0662.htm. Acesso em: 6 out. 2018.

BRASIL. Lei $n^{\circ}$ 9.093, de 12 de Setembro de 1995. Dispõe sobre feriados. Brasília: Presidência da República, 1995. Disponível em: http://www.planalto.gov.br/CCivil_03/leis/L9093.htm. Acesso: 6 out. 2018.

BRASIL. Lei no 9.335, de 10 de Dezembro de 1996. Altera a Lei n 9.093, de 12 de setembro de 1995, que dispõe sobre feriados. Brasília: Presidência da República, $1996 . \quad$ Disponível em: http://www.planalto.gov.br/ccivil_03/leis/L9335.htm. Acesso em: 6 out. 2018. 
BRASIL. Ministério da Educação. Base nacional comum curricular: ensino médio. Brasília: MEC, 2017.

BRASIL. Ministério da Educação. Secretaria de Educação Fundamental. Parâmetros curriculares nacionais: história. Brasília: MEC: SEF, 1998.

BRASIL. Ministério da Educação. Secretaria de Educação Média e Tecnológica. Parâmetros curriculares nacionais: ensino médio. Brasília: MEC, 1999.

BRITO, Adilson Junior Ishihara. "Viva a Liberté!": cultura política popular, revolução e sentimento patriótico na independência do Grão-Pará, 1790-1824. 2008. Dissertação (Mestrado em História Social) - Universidade Federal de Pernambuco, Recife, 2008.

CASSIANO, Célia Cristina de Figueiredo. Política e economia do livro didático no século XXI: globalização, tecnologia e capitalismo na educação básica nacional. In: ROCHA, Helenice; REZNIK, Luis; MAGALHÃES, Marcelo de Souza (org.). Livros didáticos de história: entre políticas e narrativas. Rio de Janeiro: FGV Editora, 2017. p. 83-100.

CERRI, Luis Fernando. Ensino de história e consciência histórica. Rio de Janeiro: Editora FGV, 2011.

CERRI, Luis Fernando. Saberes históricos diante da avaliação do ensino: notas sobre conteúdos de história nas provas do Exame Nacional do Ensino Médio ENEM. Revista Brasileira de História, São Paulo, v. 24, n. 48, p. 213-231, 2004.

CHAUÍ, Marilena. Cultura e democracia: o discurso competente e outras falas. São Paulo: Cortez, 2006.

COELHO, Geraldo Mártires. Anarquistas, demagogos e dissidentes: a imprensa liberal no Pará de 1822. Belém: CEJUP, 1993.

COELHO, Marcelo. Roteiro pronto para o golpe militar. Folha de São Paulo, São Paulo, 19 set. 2018.2 Disponível em: https://www1.folha.uol.com.br/colunas/marcelocoelho/2018/09/roteiro-prontopara-o-golpe-militar.shtml. Acesso em: 19 fev. 2019.

COX, Robert. Social forces, states and world orders: beyond international relations theory. Millenium: jornal of international studies, [S. I.], v. 10, n. 2, p. 126-155, 1981.

DELEUZE, Gilles; GUATTARI, Félix. Mil platôs: capitalismo e esquizofrenia. São Paulo: Editora 34, 1997. v. 5.

DOIMO, Ana Maria. A vez e a voz do popular: movimentos sociais e participação política no Brasil pós-70. Rio de Janeiro: Relume-Dumará: ANPOCS, 1995.

ESTUDANTES denunciam abandono de escola. DOL, Pará, 27 nov. 2015. Disponível em: $\quad$ http://www.diarioonline.com.br/noticias/policia/noticia-351704-.html. Acesso em: 23 fev. 2019. 
EVENTOS no Pará lembram 20 anos do massacre de Eldorado dos Carajás. G1 Pará, Pará, 11 abr. 2016.2 Disponível em: http://g1.globo.com/pa/para/noticia/2016/04/eventos-no-para-lembram-20anos-do-massacre-de-eldorado-dos-carajas.html. Acesso em: 6 out. 2018.

FONSECA, Selva Guimarães. Didática e prática de ensino de história: experiências, reflexões e aprendizados. Campinas: Papirus, 2003.

FONSECA, Thais Nívia de Lima e. História \& ensino de história. 2. ed. Belo Horizonte: Autêntica, 2004.

GABRIEL, Carmem Teresa. Cultura histórica nas tramas da didatização da cultura escolar (ou para uma outra definição de didática da história). In: ROCHA, Helenice; MAGALHÃES, Marcelo; GONTIJO, Rebeca (org.). O ensino de história em questão: cultura histórica, usos do passado. Rio de Janeiro: FGV Editora, 2015. p. 77-96.

GIDDENS, Anthony. Modernidade e identidade. Rio de Janeiro: Jorge Zahar Editor, 2002.

GÓMEZ CARRASCO, Cosme J.; MOLINA PUCHE, Sebastián. Narrativas nacionales y pensamiento histórico en los libros de texto de educación secundaria de España y Francia: análisis a partir del tratamento de los contenidos de la Edad Moderna. Vínculos de História, Castilla-La Mancha, n. 6, p. 206-229, 2017.

GREEN, James N. Brasil: passado e presente e ironias da história. In: MATTOS, Hebe; BESSONE, Tânia; MAMIGONIAN, Beatriz G. (org.). Historiadores pela democracia: o golpe de 2016 e a força do passado. São Paulo: Alameda, 2016. p. 122-124.

GREEN, James N. Golpes e intervenções: 1962, 1964 e 2016. In: MACHADO, André Rob. In: MACHADO, André Roberto de Arruda; TOLEDO, Maria Rita de Almeida (orgs.). Golpes na história e na escola: o Brasil e a América Latina nos Séculos XX e XXI. São Paulo: Cortez; ANPUH SP, 2017, p. 32-48.

HUNTINGTON, Samuel P. Robust nationalism. The National Interest, [S. I.], 1 dec. 1999. Disponível em: https://nationalinterest.org/article/robust-nationalism-698. Acesso em: 16 out. 2018.

IBGE. Ananindeua: população. Rio de Janeiro: IBGE, 2016. Disponível em: https://cidades.ibge.gov.br/brasil/pa/ananindeua/panorama. Acesso em: 28 fev. 2019.

LAVILLE, Christian. A guerra das narrativas: debates e ilusões em torno do ensino de História. Revista Brasileira de História, São Paulo, v. 19, n. 38, p. 125-138, 1999.

LOWENTHAL, David. Como conhecemos o passado. Projeto História, São Paulo, v. 17, p. 63-201, nov. 1998.

MACHADO, André Roberto de Arruda. A quebra da mola real das sociedades: a crise política do antigo regime português na Província do Pará (1821-1825). 2006. 
Tese (Doutorado em História Social) - Universidade de São Paulo, São Paulo, 2006.

MAGALHÃES, Marcelo de Souza. Apontamentos para pensar o ensino de história hoje: reformas curriculares, ensino médio e formação do professor. Tempo, Niterói, v. 11, n. 21, p. 49-64, jun. 2006 . Disponível em: http://www.scielo.br/scielo.php?script=sci_arttext\&pid=S1413-

77042006000200005\&lng=en\&nrm=iso. Acesso em: 18 fev. 2019.

MANN, Michael. Estados nacionais na Europa e noutros continentes: diversificar, desenvolver, não morrer. In: BALAKRISHNAN, Gopal (org.). Um mapa da questão nacional. Rio de Janeiro: Contraponto, 2000. p. 311-334.

MATTOS, Hebe; BESSONE, Tânia; MAMIGONIAN, Beatriz G. (org.). Historiadores pela democracia: o golpe de 2016 e a força do passado. São Paulo: Alameda, 2016.

MCLUHAN, Herbert M.; POWERS, Bruce. R. La aldea global: transformaciones en la vida y los medios de comunicación mundiales en el siglo XXI. 2. ed. Barcelona: Editorial Gedisa, 1993.

MUNAKATA, Kazumi. Histórias que os livros didáticos contam, depois que acabou a ditadura no Brasil. In: FREITAS, Marcos Cézar (org.). Historiografia brasileira em perspectiva. 3. ed. São Paulo: Contexto, 2000. p. 271-298.

MUNIZ, João de Palma (org.). Adesão do Grão-Pará à independência e outros ensaios. Belém: Conselho Estadual de Cultura, 1973.

NADAI, Elza. O ensino de História e a "pedagogia do cidadão". In: PINSKY, Jaime (org. ). O ensino de história e a criação do fato. 14. ed. São Paulo: Contexto, 2011. p. 27-36.

NAPOLITANO, Marcos; RIBEIRO, David. Crises políticas: o "golpismo atávico" na história recente do Brasil. In: MACHADO, André Roberto de A.; TOLEDO, Maria Rita de Almeida (org.). Golpes na história e na escola. São Paulo: Cortez: Anpuh, 2017. p. 49-74.

NEVES, Lucas. Eleição de Bolsonaro marca fim da Nova República, diz historiadora. Folha de São Paulo, São Paulo, 4 nov. 2018. Disponível em: https://www1.folha.uol.com.br/ilustrissima/2018/11/eleicao-de-bolsonaromarca-fim-da-nova-republica-diz-historiadora.shtml. Acesso em: 19 fev. 2019.

NORA, Pierre. Entre memória e história: a problemática dos lugares. Projeto História, São Paulo, v. 10, p. 7-28, dez. 1993.

OEIRAS, José Matheus da Costa. Adesão do Pará à independência: significados de uma efeméride no espaço escolar. [S. I.: s. n.], 2018. Relatório técnico-científico PIBIC - ensino médio. 
OZOUF, Mona. A festa, sob a Revolução Francesa. In: LE GOFF, Jacques; NORA, Pierre (dir.). História: novos objetos. 4· ed. Rio de Janeiro: Francisco Alves, 1974. p. 216-232.

OZOUF, Mona. Innovations et traditions dans les itinéraires des fêtes révolutionnaires: I'exemple de Caen. Ethnologie Française, Paris, v. 7, n. 1, p. 45$54,1977$.

PARÁ. Lei No 5.999, de 10 de Setembro de 1996. Declara o dia 15 de agosto data magna do Estado do Pará e dá outras providências. Belém: Governo do Estado, 1996. Disponível em: http://www.pge.pa.gov.br/sites/default/files/lo5999.pdf. Acesso em: 6 out. 2018.

PINSKY, Jaime (org.). O ensino de história e a criação do fato. 14. ed. São Paulo: Contexto, 2011.

PROTESTO Alunos/Prof. Gondim Lins 22/09. Por Gustavo. [S. I.: s. n.], 2017. 1 vídeo (2min39). Disponível em: https://www.youtube.com/watch?v=7RW9P5Rm6Vg. Acesso em: 21 fev. 2019.

RAMOS, Maria Elisa Teté. O ensino de História e a questão do multiculturalismo depois dos Parâmetros Curriculares Nacionais. In: CERRI, Luís Fernando (org.). Ensino de história e educação: olhares em convergência. Ponta Grossa: UEPG, 2007. p. 93-112.

RÜSEN, Jörn. História viva: teoria da história: formas e funções do conhecimento histórico. Brasília: Universidade de Brasília, 2007.

SADER, Eder. Quando novos personagens entraram em cena: experiências, falas e lutas dos trabalhadores da Grande São Paulo, 1970-80. Rio de Janeiro: Paz e Terra, 1988.

SÁNCHEZ GAMBOA, Silvio. A globalização e os desafios da educação no limiar do novo século: um olhar desde a América Latina. In: LOMBARDI, José Claudinei (org.). Globalização, pós-modernidade e educação: história, filosofia e temas transversais. Campinas: Autores Associados HISTEDBR; Caçador: UnC, 2001. p. 79-106.

SANFELICE, José Luis. Pós-modernidade, globalização e educação. In: LOMBARDI, José Claudinei (org.). Globalização, pós-modernidade e educação: história, filosofia e temas transversais. Campinas: Autores Associados HISTEDBR; Caçador: UnC, 2001. p. 13-38.

SARLO, Beatriz. Tiempo pasado: cultura de la memoria y giro subjetivo: una discusión. Buenos Aires: Siglo Veintiuno Editores, 2012.

SCHERER-WARREN, Ilse. Redes de movimentos sociais. São Paulo: Edições Loyola, 1993. 
SCHIMIDT, Maria Auxiliadora Moreira dos Santos. Cultura histórica e cultura escolar: diálogos a partir da educação histórica. História Revista, Goiânia, v. 17, n. 1, p. 91-104, jan./jun. 2012.

SILVA, Marcos Antônio da; FONSECA, Selva Guimarães. Ensino de história hoje: errâncias, conquistas e perdas. Revista Brasileira de História, São Paulo, v. 31, n. 60, p. 13-33, 2010.

SOARES, Marco Antonio Neves. O Ensino de história presente nos parâmetros curriculares nacionais do ensino médio (PCNEM): a construção do sujeito adequado. História \& Ensino, Londrina, v. 8, p. 29-44, out. 2002.

SOUZA JUNIOR, José Alves de. Constituição ou revolução: os projetos políticos para a emancipação do Grão-Pará e a atuação política de Fillippe Patroni (18201823). Campinas-SP: Unicamp, 1997.

TELES, Janaína de Almeida. Brasil e Argentina: transição democrática e promoção da justiça em perspectiva comparada. In: MACHADO; André Roberto de Arruda; TOLEDO, Maria Rita de Almeida. Golpes na história e na escola: o Brasil e a América Latina nos séculos XX e XXI. São Paulo: Cortez: ANPUH, 2017. p. 110-139.

Recebido em 04 de abril de 2019 Aprovado em 26 de novembro de 2020 